Yüzüncü Yil Üniversitesi
Tarim Bilimleri Dergisi

Araştırma Makalesi (Research Article)

\title{
Bıldırcınlarda Yumurta Kalite Özellikleri Arasındaki İlişkilerin Veri Madenciliği Yöntemleri ile İncelenmesi
}

\author{
Şenol ÇELIK ${ }^{* 1}$, Turgay ŞENGÜL ${ }^{1}$, A. Yusuf ŞENGÜL ${ }^{1}$
}

${ }^{1}$ Bingöl Üniversitesi, Ziraat Fakültesi, Zootekni Bölümü, 12000, Bingöl, Türkiye

*Sorumlu yazar e-posta: senolcelik@bingol.edu.tr

\section{Makale Bilgileri}

Geliş: 19.06.2019

Kabul: 08.08.2019

Online Yayınlanma 30.09.2019

DOI: 10.29133/yyutbd.580064

\section{Anahtar kelimeler}

Bildırcin,

CART,

CHAID,

Yumurta kalitesi.
Öz: Bu çalışmada, bıldırcınlarda bazı yumurta kalite özellikleri (şekil indeksi, kabuk kalınlığı, kabuk ağırlığı, ak indeksi, ak yüksekliği, sarı indeksi, sarı yüksekliği, özgül ağılık ve Haugh birimi) ile yumurtanın sarı ve ak ağırlığı arasındaki ilişkiler CHAID (Chi-Squared Automatic Interaction Detection), Geniş CHAID ve CART (Classification and Regression Trees) algoritmaları kullanılarak incelenmiştir. CHAID, Geniş CHAID ve CART algoritmaları normallik, doğrusallık, homojenlik vb. varsayımları gerektirmediğinden önemli avantajlara sahiptirler. Yöntemlerin karşılaşıııılmasında belirleme katsayısı $\left(\mathrm{R}^{2}\right)$, düzeltilmiş belirleme katsayısı $\left(\bar{R}^{2}\right)$, Hata Kareler Ortalamasının Karekökü (RMSE) ve Ortalama mutlak yüzde hata (MAPE) kriterleri kullanılmıştır. Sonuç olarak, yumurtaların sarı ağırlığı üzerine etkili olan yumurta kalite özelliklerinin belirlenmesinde en uygun yöntemin CHAID algoritması olduğu saptanmıştır. $\mathrm{Bu}$ yöntemle, en yüksek sarı ağırlığı, yumurta ağırlığının 13,36 g'dan fazla ve şekil indeksinin $0,895^{\prime}$ ten daha yüksek olduğu gruptan elde edilmiş̧tir. Ak ağırlığını etkileyen kalite özelliklerini belirlemede ise, en uygun yöntem CART algoritması olmuştur. Bu yönteme göre, en yüksek yumurta ak ağırlı̆̆ı, yumurta ağırlığının 12.47 g'dan fazla, ak indeksinin 0,326 ve şekil indeksinin 0,865 olduğu gruptan elde edilmiştir.

\section{Analysis by Data Mining Methods of Relationships among Egg Quality Characteristics in Japanese Quails}

\section{Article Info}

Received: 19.06.2019

Accepted: 08.08.2019

Online Published 30.09.2019

DOI: $10.29133 /$ yyutbd.580064

\section{Keywords}

Quail,

CART,

CHAID

Egg quality.

\begin{abstract}
This study examined the relationships between some egg quality characteristics in quails (shape index, shell thickness, shell weight, egg white index, egg white height, yolk index, yolk height and Haugh unit) and the yolk and white weights of eggs by using the CHAID (Chi-Squared Automatic Interaction Detection), Extended CHAID and CART (Classification and Regression Trees) algorithms. The CHAID, Extended CHAID and CART algorithms have significant advantages as they do not require assumptions such as normality, linearity and homogeneity. The methods were compared by using the criteria of coefficient of determination $\left(\mathrm{R}^{2}\right)$, adjusted coefficient of determination $\left(\bar{R}^{2}\right)$ and Root Mean Square Error (RMSE). As a result, the most suitable method for determining the egg quality characteristics that are effective on the yolk weight of eggs was found to be the CHAID algorithm. With this method, the highest yolk weight was obtained from the group where egg weight was higher than $13.36 \mathrm{~g}$, and the shape index was higher than 0.895 . For determining the quality characteristics that affect egg white weight, the most suitable method was found to be the CART algorithm. With this method, the highest egg white weight was obtained from the group where egg weight was higher than $12.47 \mathrm{~g}$, the egg white index was 0.326 , and the shape index was 0.865 .
\end{abstract}




\section{Giriş}

Bıldırcın yetiştiriciliği, son yıllarda ülkemizde gittikçe önem kazanan ve yaygınlaşan bir hayvansal üretim koludur. Bıldırcın yetiştiriciliğinde hem yumurta ve hem de et üretimi büyük öneme sahiptir. Bıldırcın ürünleri gerek lezzetli oluşu ve gerekse besleme değerlerinin yüksek olması nedeniyle tüketiciler tarafindan büyük ölçüde talep görmektedir. Bu nedenle, konuyla ilgili çalışmalar genellikle bıldırcınlarda yumurta verimi ve besi performansı üzerine yoğunlaşmıştır. Bıldırcınlarda yumurta verimini etkileyen faktörler ve yumurta kalitesi üzerine çok sayıda çalışma olmasına karşılık, yumurtaların kalite özellikleri arasındaki ilişkilerin belirlenmesi ve bu özelliklerin kalite üzerine etkileri konusundaki çalışmalar henüz çok yetersizdir. Bu nedenle, bu konuda yapılacak olan çalışmalardan elde edilecek sonuçların en uygun analiz yöntemleri ile incelenmesinde yarar vardır.

Son zamanlarda, birçok alanda başarıyla kullanılan analiz yöntemlerinden biri de Veri Madenciliği algoritmasıdır. Veri Madenciliği veri miktarındaki artışla beraber çokça ilgi görmeye başlayan yöntemlerden biridir. Hayvancılığın farklı konularında Veri Madenciliği uygulanarak yapılmış çalışmalar mevcuttur (Khan ve ark., 2014; Ali ve ark., 2015; Eyduran ve ark., 2017; Çelik ve Y1lmaz, 2018; Balta ve Topal, 2018).

Orhan ve ark. (2016) CHAID algoritması kullanarak yaptıkları çalışmada, tavuklarda yumurta ak1 ağırlı̆̆ 1 , sarı ağırlığ1 ve kabuk ağırlığının yumurta ağırlığı üzerinde etkili olduğunu bildirmişlerdir. Çelik ve ark. (2017) bıldırcınlarda yumurta akı ağırlığı, sarı indeksi ve sarı ağırlığının yumurta ağırlığını etkilediğini ve yumurta ağırlı̆̆ını tahmin için en iyi algoritmanın Geniş CHAID olduğunu ifade etmişlerdir. Gevrekçi ve Takma (2018), ticari yumurta tavuklarında yumurta verimi ve yumurta verimini etkileyen faktörleri CHAID ve CART algoritmaları ile incelemişler ve uygulanacak yetiştirme programlarında bir ön bilgi olarak CART algoritmasının gerekli olduğunu bildirmişlerdir. Duru ve ark. (2017), ticari yumurtacı tavuklarda, yumurta kalite özellikleri arasındaki ilişkileri regresyon ağacı yöntemleri ile incelemiş̧ler ve gerek yemeklik gerekse kuluçkalık yumurta üretiminde karlılık üzerine önemli etkisi olan yumurta kalite özellikleri arasındaki ilişkilerin ortaya konulmasında CHAID analizinin daha uygun olduğunu açıklamışlardır.

Bu çalışmada, bıldırcın yumurtalarında yumurta akı ve sarı ağırlığı üzerine etkili olan bazı iç ve dış kalite özelliklerinin farklı veri madenciliği yöntemleri ile incelenmesi amaçlanmıştır.

\section{Materyal ve Yöntem}

\section{Materyal}

Çalışmanın materyalini, Bingöl Üniversitesi Ziraat Fakültesi Zootekni Bölümü kanatlı hayvan ünitesinde yetiştirilmekte olan 10 haftalı yaştaki bıldırcınlardan (Coturnix coturnix japonica) elde edilen 190 adet yumurta oluşturmuştur. Tartımlar için $0.001 \mathrm{~g}$ hassasiyetle ölçüm yapan elektronik bir terazi, yumurtaların en ve boy ölçümleri için dijital kumpas, yumurtanın iç kalitesini belirlemek için yüzeyine cam yerleştirilmiş ve eğimi ayarlanmış bir masa, sarı ve ak yükseklikleri için üç ayaklı bir mikrometre ve kabuk kalınlığını ölçmek için de bu amaçla üretilmiş olan dijital bir mikrometre kullanılmıştır.

\subsection{Yöntem}

İncelenen yumurtalar, kanatlı ünitesinden 3 gün süreyle toplanmış ve 24 saat oda sıcaklığında bekletildikten sonra ölçümleri yapılmıştır. Yumurtalar önce numaralandırılarak tartılmış ve yumurta ağırlığı belirlenmiştir. Daha sonra, yumurtaların eni ve boyu ölçülmüştür. Bu işlemlerden sonra, yumurtalar hazırlanan masadaki camın üzerine kırıldıktan 10 dakika sonra iç kalite ile ilgili ölçümler yapılmıştır. Yumurtanın sarı ağırlığı, yumurta sarısının yumurta akından ayrılarak tartılmasıyla saptanmıştır. Diğer yandan, yumurta kabukları, suda yıkanarak kalıntılardan temizlenmiş ve 24 saat oda sıcaklığında kurutulmuştur. Kuruyan kabuklar, kabuk zarları ile birlikte önce tartılarak ağırlıkları saptanmıştır. Daha sonra yumurtanın sivri, küt ve orta kısımlarından olmak üzere üç farklı yerden kabuk kalınlıkları ölçülmüş ve bu üç ölçümün ortalamasıyla kabuk kalınlığı tespit edilmiştir. Özgül ağırlık, yumurtanın önce havadaki ağırlığı ve daha sonra saf su içindeki ağırlığı tartılarak belirlenmiştir. Yapılan ölçümlerde aşağıdaki formüller kullanılarak gerekli hesaplamalar yapılmıştı;; 
Şekil indeksi $=$ Yumurta genişliği x 100/yumurta uzunluğu

Ak ağırlığ $1=$ Yumurta ağırlığı $-($ kabuk ağırlığ $1+$ sar1 ağırlığ 1$)$

Sarı indeksi = Yumurta sarısının yüksekliği $(\mathrm{mm})$ /yumurta sarısının çapı $(\mathrm{mm})$

Ak indeksi $=$ Ak yüksekliği (mm) x 100/ak uzunluğu ve genişliğinin ortalaması (mm)

Özgül ağırlık $\left(\mathrm{g} / \mathrm{cm}^{3}\right)=\frac{\text { Yumurtanın havadaki ağırlığı (g) }}{\text { (yumurtanın havadaki ağırlığı }(\mathrm{g})-\text { saf sudaki ağırlığı }(\mathrm{g}))}$

Haugh Birimi $=100 \log \left(\mathrm{H}+7.57-1.7 \mathrm{~W}^{0.37}\right)$

$\mathrm{H}=\mathrm{Ak}$ yüksekliği,

W=Yumurta ağırlığı (Csuka ve Ledec, 1981).

Araştırmada ele alınan özellikler; yumurta ağırlığı (YA), şekil indeksi (Şİ), ak indeksi (AK), sarı indeksi (Sİ) sarı ağırlığı (SA), ak ağırlığı (AA), kabuk kalınlığı (KK), kabuk ağırlığı (KA) ak yüksekliği (AK), özgül ağırlık (ÖA) ve Haugh birimi (HB) olarak kodlanmıştır.

Bıldırcınlarda yumurtanın sarı ve ak ağırlığı ile diğer kalite özellikleri arasındaki ilişkilerin belirlenmesinde regresyon ağacı olarak ifade edilen Veri Madenciliği yöntemleri kullanılmıştır. Regresyon ağacı yönteminin kullanılma nedeni, bağımsız değişkenlerin dağılımı ile ilgili herhangi bir varsayım gerektirmemesi, çoklu bağlantılı olma durumu, aykırı değerler ve kayıp gözlemlerden etkilenmemesi gibi avantajlara sahip olmasıdır (Mendeş ve Akkartal, 2009). Çalışmada kullanılan algoritmalar aşağıda verilmiştir.

CHAID algoritması, güçlü bir öteleme algoritması ile bütün olan evren, kararlı alt düğümlere bölünebildiğinden, elde edilecek bir regresyon denklemi klasik varsayımlardan (normallik, doğrusallık, homojenlik vb.) bağımsız tutulmaktadır. Bu yöntem, güçlü bir öteleme algoritması ile bütün olan evren, kararlı alt dügümlere bölünebildiğinden, elde edilecek bir regresyon denklemi, normallik, doğrusallık, homojenlik vb. gibi varsayımlardan bağımsız tutulmaktadır. $\mathrm{Bu}$ işlem ile verilerin dağılımında normallik ve homojenlik sağlanabilmektedir. Ayrıca CHAID analiziyle sürekli ve kategorik veriler, aynı anda modele dahil edilebilmektedir (Koyuncugil, 2007).

Geniş CHAID algoritması, Biggs ve ark., (1991) tarafindan geliştirilen ve birleştirme, bölünme ve durma aşamalarına sahip olan bu algoritma, kök düğümden başlayarak yinelemeli olarak homojen dügümler oluşturur ve bu dügümler arası/içi varyans arttırılır/azaltılır (Nisbet ve ark., 2009).

CART algoritması ise, Breiman ve ark., (1984) tarafından geliştirilen ve veri setindeki bütün bireyleri içine alan kök dügü̈mden başlayarak, yinelemeli olarak homojen düğümler elde edilene kadar her aşamada bir düğümden sadece iki yavru düğüm şeklinde bölünen ikili karar ağacı algoritmasıdır. CART önemli olan bağımsız değişkenleri otomatik olarak ağaç yapısına dahil eder (Nisbet ve ark., 2009).

Kullanılan yöntemlerin karşılaştırılmasında, belirtme katsayısı $\left(\mathrm{R}^{2}\right)$, düzeltilmiş belirtme katsayısı $\left(\bar{R}^{2}\right)$ ve Hata Kareler Ortalamasının Karekökü (RMSE) gibi kriterler kullanılmıştır (Takma ve ark., 2012; Grzesiak ve Zaborski, 2012; Eyduran ve ark., 2019). Bu kriterler aşağıdaki gibi ifade edilmekte ve en yüksek $\mathrm{R}^{2}$ ve $\bar{R}^{2}$ ile en düşük RMSE ve MAPE değerlerine sahip olan yöntem en uygun olarak kabul edilmektedir.

$$
\begin{gathered}
\text { Belirleme katsayısı (\%) } \\
R^{2}=1-\frac{\sum_{i=1}^{n}\left(Y_{i}-\hat{Y}_{i}\right)^{2}}{\sum_{i=1}^{n}\left(Y_{i}-\bar{Y}\right)^{2}} \\
\text { Düzeltilmiş belirleme katsayıs1 (\%) } \\
\bar{R}^{2}=1-\frac{\frac{1}{n-k-1} \sum_{i=1}^{n}\left(Y_{i}-\hat{Y}_{i}\right)^{2}}{\frac{1}{n-1} \sum_{i=1}^{n}\left(Y_{i}-\bar{Y}\right)^{2}}
\end{gathered}
$$

Hata kareler ortalamasının karekökü (RMSE)

$$
\begin{aligned}
R M S E & =\sqrt{\frac{1}{n} \sum_{i=1}^{n}\left(Y_{i}-\hat{Y}_{i}\right)^{2}} \\
& \text { Ortalama mutlak yüzde hata (MAPE) }
\end{aligned}
$$$$
M A P E=\frac{1}{n} \sum_{i=1}^{n}\left|\frac{\varepsilon_{i}}{Y_{i}}\right| \cdot 100
$$ 
$\mathrm{Bu}$ formüllerde, n: Gözlem sayısı, $\mathrm{Y}_{\mathrm{i}}$ : Bağımlı değişken, $\widehat{Y}_{i}$ : Bağımlı değişkenin tahmini değeri, $\varepsilon_{i}$ : Hata terimleridir.

\section{Bulgular}

Bıldırcın yumurtalarında sarı ve ak ağırlığı üzerine etkili olan diğer kalite özelliklerini belirlemek için CHAID, Geniş CHAID ve CART algoritmaları uygulanmıştır. Sarı ağırlığı tahmin etmede en uygun algoritmayı tespit etmek için, $\mathrm{R}^{2}, \bar{R}^{2}$ RMSE, MAPE gibi uyum iyiliği kriterleri hesaplanmıştır. CHAID, Geniş CHAID ve CART algoritmaları için sırasıyla; $\mathrm{R}^{2}$ değerleri 0.819 , 0.815, 0.587; $\bar{R}^{2}$ değerleri, 0.813, 0.809, 0.573; RMSE değerleri 0.426, $0.430,0.643$ ve MAPE değerleri 5.159, 5.479, 5.845 olarak bulunmuştur. Analiz sonucunda, en uygun bulunan CHAID algoritması için aşağıdaki bulgular saptanmıştır.

Yumurtada sarı ağırlı̆̆ını etkileyen diğer kalite özelliklerini belirlemede en uygun bulunan algoritma CHAID olmuştur. Yumurta sarı ağırlığını tahmin etmek için oluşturulan regresyon ağacı başlangıçta 6 düğüme ayrılmıştır. Sarı ağırlığı için, Düğüm 1, YA $\leq 11,05$ g; Düğüm 2; $11.05<\mathrm{YA} \leq 11.26 \mathrm{~g} ;$ Dügüum 3, $11.26<\mathrm{YA} \leq 12.00 \mathrm{~g} ;$ Düğüm 4, $12.00<\mathrm{YA} \leq 12.44 \mathrm{~g} ;$ Düğüm 5, $12.44<\mathrm{YA} \leq 13.36 \mathrm{~g}$ ve Düğüm 6 , YA $>13.36 \mathrm{~g}$ olan yumurtaların oluşturduğu alt gruplara ayrılmıştır. Regresyon ağacında Düğüm 1'den 6'ya doğru gidildiğinde, yumurta ağırlığı arttıkça sarı ağırlığında (3.421-4.938 g) artış gözlenmiştir. Sonraki düğümlerde ise, Düğüm 7, Şİ $\leq 0.676$, Düğüm 8, $0.676 \leq S ̧ \dot{I} \leq 0.719$ ve Düğüm 9 ŞI $>0.719$ olan yumurtaların oluşturduğu alt grubu temsil etmektedir. Düğüm 10, Ş่ $\leq 0,887$ ve Dügüm 11 ise Ş̧ $>0.887$ olan yumurtaların oluşturduğu alt grubu temsil etmektedir. Ak ağırlığı, YA>13.36 g ve Ş $\mathrm{I} \leq 0.895$ tarafindan etkilenmiştir (Adj. $\mathrm{P}=0.000$ ve $\mathrm{F}=30.150$ ). Yumurta ağırlığının (Adj. $\mathrm{P}=0,000, \mathrm{~F}=62.100$ ), sarı indeksinin (Adj. $\mathrm{P}=0.000, \mathrm{~F}=19.746$ ), şekil indeksinin (Adj. $\mathrm{P}=0.000, \mathrm{~F}=37.903$ ) ve ak ağırlığının (Adj. $\mathrm{P}=0.007, \mathrm{~F}=13.344$ ve Adj. $\mathrm{P}=0.000$, $\mathrm{F}=30.150$ ) sarı ağırlığına etkili olduğu görülmüştür. En yüksek sarı ağırlığı, YA>13.36 g, Şİ>0.895 (5.509 g) olan gruptan (5.035 g) elde edilmiştir. Şekil 1'de yumurta sarı ağırlığını etkileyen kalite özellikleri gösterilmiştir.

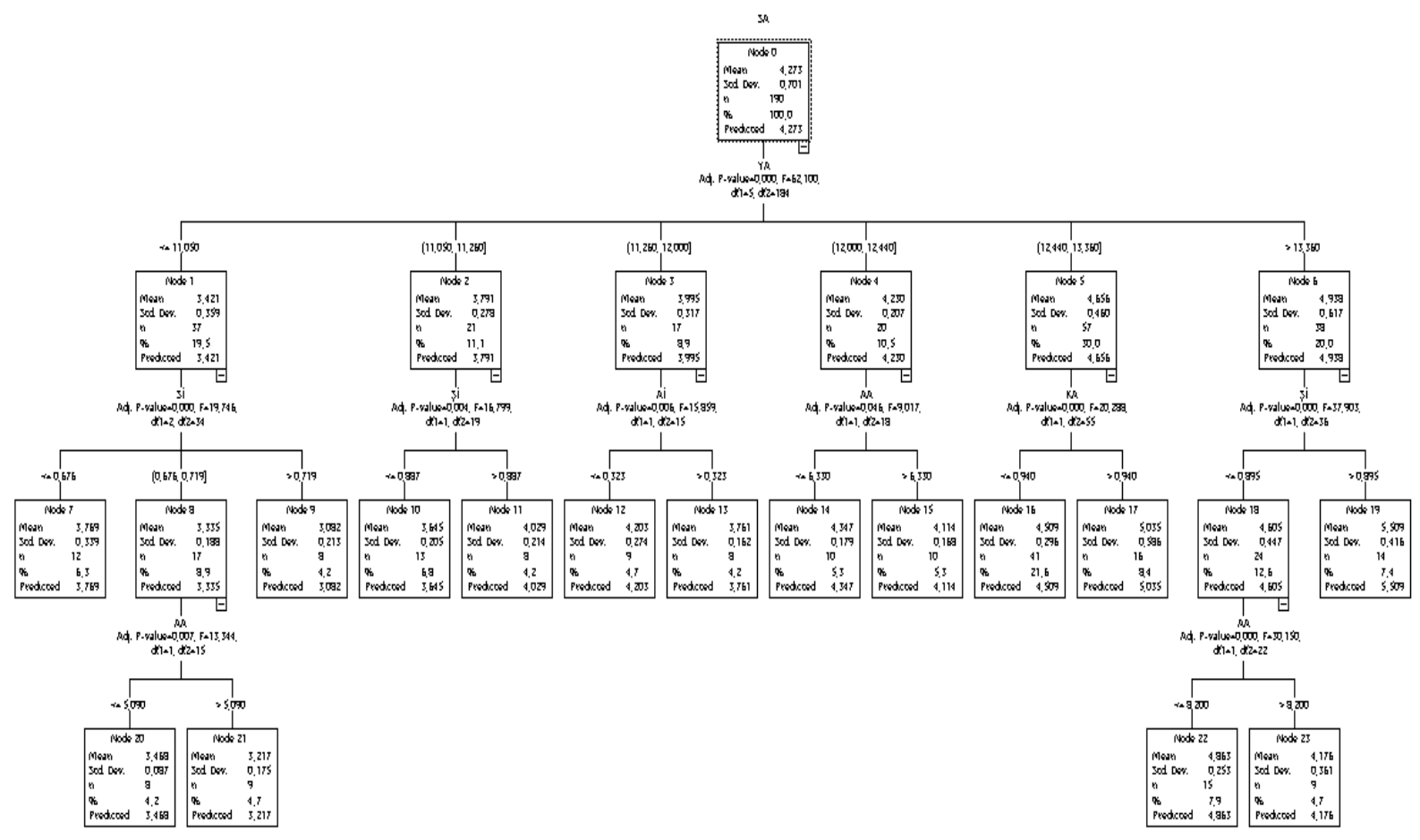

Şekil 1. CHAID algoritması ile yumurtanın sarı ağırlığı tahmini.

Ak ağırlığını etkileyen özellikleri belirlemek için CHAID, Geniş CHAID ve CART algoritmaları için ve değerleri sırasıyla, $\mathrm{R}^{2} ; 0.785,0.774,0.810 ; \bar{R}^{2} ; 0.783,0.772,0.808$; RMSE; 
0.464, 0.476, 0.437 ve MAPE; 6.854, 6.902, 6.021 olarak bulunmuştur. Analiz sonucunda, en uygun bulunan CART algoritması için aşağıdaki bulgular saptanmıştır.

Ak ağırlığını tahmin etmek için oluşturulan karar ağacı çeşitli düğümlere ayrılmıştır. Ak ağırlığı için, Dügüm 1, YA $\leq 12.47 \mathrm{~g}$ ve Düğüm 2, YA $>12.47 \mathrm{~g}$ olan yumurtalar alt grupları oluşturmuştur. Düğüm 7, YA $\leq 12.47 \mathrm{~g}, \mathrm{YA} \leq 11.96 \mathrm{~g}$ ve $\mathrm{YA} \leq 11.20 \mathrm{~g}$, Düğüm $8, \mathrm{YA} \leq 12.47 \mathrm{~g}, \mathrm{YA} \leq 11.96 \mathrm{~g}$ ve

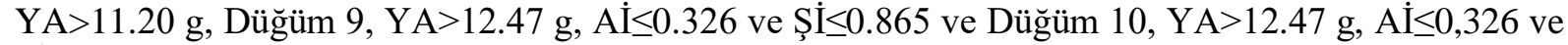
Ş $>0.865$ olan yumurtaların oluşturduğu alt grubu temsil etmektedir. En yüksek ak ağırlığı, YA>12.47 g, A $\dot{I} \leq 0.326$ ve Ş $\dot{I}>0.865$ olan gruptan $(8.016 \mathrm{~g})$ elde edilmiştir. Şekil 2'de yumurta ak ağırlığını etkileyen kalite özellikleri gösterilmiştir.

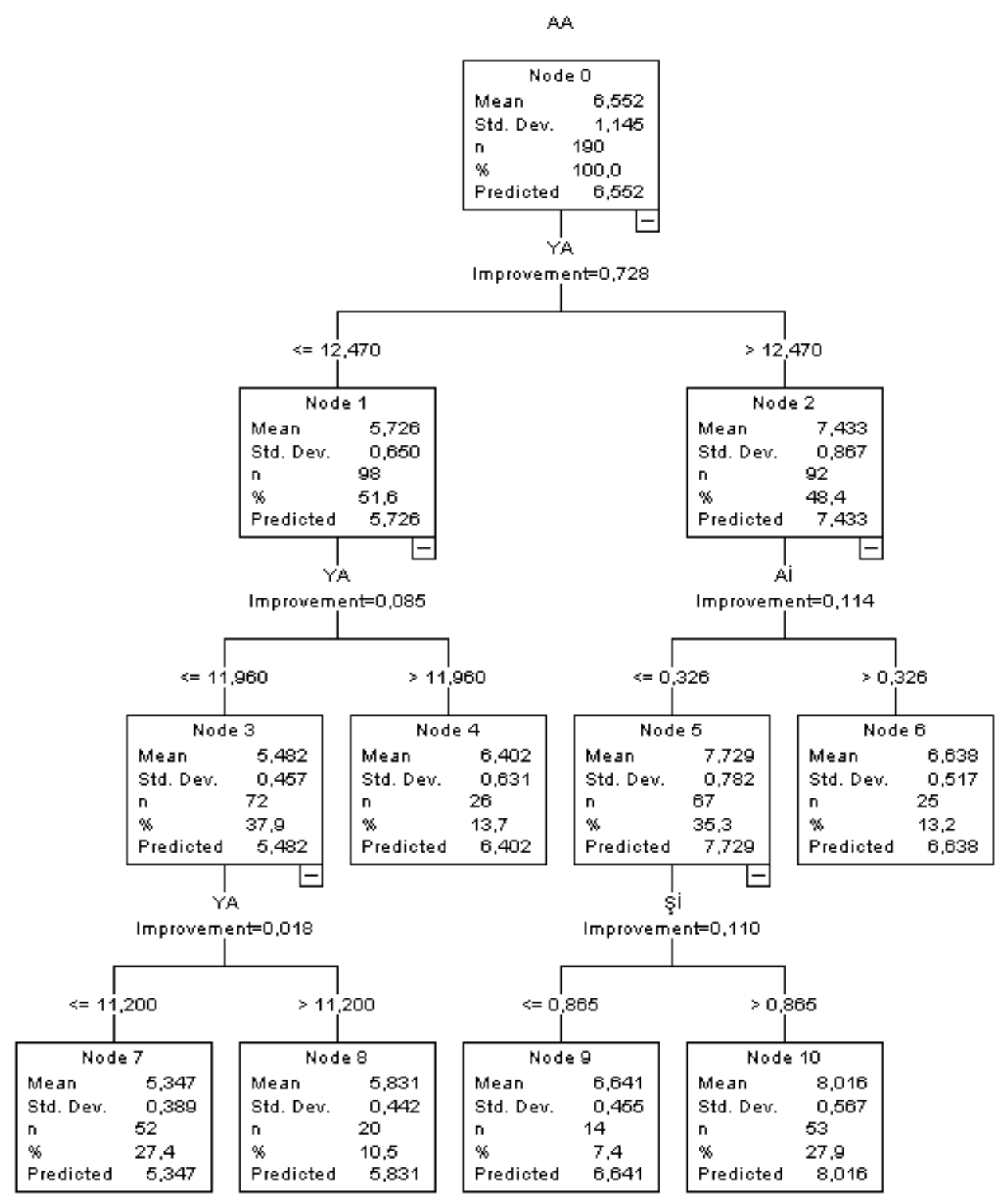

Şekil 2. CART algoritması ile yumurtanın ak ağırlığı tahmini.

\section{Tartışma ve Sonuç}

Çelik ve ark. (2017), bıldırcınlarda yumurta ağırlığını tahmin için en iyi algoritmanın Geniş CHAID olduğunu ifade etmişlerdir. Söz konusu çalışmada, yumurta ağırlığını ak ağırlı̆̆ı, sarı indeksi 
ve sarı ağırlığı etkilemiş olup, en yüksek yumurta ağırlığı ak ağırlığının 8.09 g'dan fazla olduğu (13.516 g) durumda tahmin edilmiştir. Orhan ve ark. (2016), tavuklarda yumurta ağırlığını CHAID algoritması ile tahmin etmişler ve yumurta ağırlığının en fazla sırasıyla, ak ağırlığı, sarı ağırlığı ve kabuk ağırlığı tarafindan etkilendiğini belirtmişlerdir. Açıklanan bulgularda, en yüksek yumurta ağırlığı, ak ağırlığının 41 g'dan ve sarı ağırlığının 17 g'dan daha yüksek olanlardan elde edildiği görülmektedir. Söz konusu çalışmada, $\mathrm{R}^{2}$ değeri 0.99988 olarak bulunmuştur. Gevrekçi ve Takma (2018), tavuklarda yumurta üretimini CHAID ve CART algoritmaları ile incelemişler ve RMSE değerlerini sırasıyla, 9.93 ve 11.25 olarak bildirmişlerdir. Araştırmacılar, uyum iyiliği kriterleri göz önüne alındığında, CHAID algoritmasından daha iyi sonuçlar alındığını açıklamışlardır. Duru ve ark. (2017), tavuklarda yumurta kalite özellikleri arasındaki ilişkileri yine CHAID algoritması ile incelemişler ve tavuk yaşının yumurta sarısının rengini etkilediğini tespit etmişlerdir. Aynı araştırmada, en yüksek ş̧ekil indeksi değeri, yumurta boyunun 55.05-57.50 mm değerler arasında ve yumurta eninin $43.85 \mathrm{~mm}$ 'den büyük olduğu durumda $(78.779 \mathrm{~mm})$ elde edilmiştir. Ayrıca, sarı indeksi ve Haugh birimini yaş, ak indeksini ise yaş ve yumurta boyu etkilemiştir. Oguntunji (2017), Muscovy ördeklerinin vücut ağırlığının tahmininde CART algoritmasını kullanmış olup, $\mathrm{R}^{2}$ değerini 0.910 olarak bildirmiştir.

$\mathrm{Bu}$ çalışmada, bıldırcınlarda yumurtanın sarı ve ak ağırlığını etkileyen yumurta kalite özelliklerinin etkileri ayrı ayrı incelenmiştir. Bu faktörlerin analiz ve değerlendirilmesinde, CHAID, Geniş CHAID ve CART algoritmaları kullanılmış ve elde edilen sonuçlar yorumlanmıştır. Çalışmada önce sarı ağırlığı, sonra da ak ağırlığı bağımlı değişken olarak alınmıştır. Her iki modelde de, bu algoritmalar ile oluşturulan regresyon ağaçlarında, sarı ve ak ağırlığına etki eden bağımsız değişkenler gösterilmiştir.

En yüksek sarı ağırlı̆ğ, YA>13.36 g, Şİ>0.895 olan gruptan (5.509 g) elde edilmiştir. Bunu sirasiyla, $12.44 \leq \mathrm{YA}<13.36 \mathrm{~g}, \mathrm{KA}>0.94$ olan gruptan (5.035 g) ve $\mathrm{YA}>13.36 \mathrm{~g}$ olan gruptan (4.938 g) elde edilenler izlemiş̧tir. En yüksek ak ağırlığ gruptan (8.016 g) ve $\mathrm{YA}>12.47 \mathrm{~g}$ ve $\mathrm{A} \dot{\mathrm{I}} \leq 0.326$ olan gruptan $(7.729 \mathrm{~g})$ elde edilmiştir.

Sonuç olarak, CHAID, Geniş CHAID ve CART algoritmalarının regresyon ağacı oluşturma yapıları birbirinden farklı olduğundan, bu ağaçlar arasında bazı farklılıklar görülebilmektedir. CART algoritmasında düğümler sadece ikili olarak ayrılabilirken, CHAID ve Geniş CHAID algoritmalarında dügümmler ikiden fazla sınıflara ayrılmaktadır. Çalışmada kullanılan CHAID, Geniş CHAID ve CART algoritmaları $\mathrm{R}^{2}, \bar{R}^{2}$, RMSE ve MAPE gibi uyum kriterleri bakımından çok iyi sonuçlar vermiştir. Sarı ağırlı̆̆ sonuçlar vermiştir. Yumurta kalite özelliklerini tahmin etmede veri madenciliği algoritmalarının (CHAID, Geniş CHAID ve CART) kullanımının uygun yöntemler olduğu ve sonraki çalışmalar için faydalı olabileceği umulmaktadır.

\section{Kaynakça}

Ali, M., Eyduran, E., Tariq, MM., Tirink, C., Abbas, F., Bajwa, M. A., Baloch, M. H., Nizamani, A. H., Waheed, A., Awan, M. A., Shah, S. H., Ahmad, Z. \& Jan, S. (2015). Comparison of artificial neural network and decision tree algorithms used for predicting live weight at post weaning period from some biometrical characteristics in Harnai sheep. Pakistan Journal Zool. 47(6), 1579-1585.

Balta, B. \& Topal, M. (2018). Regression tree approach for assessing the effects of non-genetic factors on birth weight of Hemşin lamb. Alınteri Journal of Agricultural Science, 33(1), 65-73.

Biggs, D., De Ville, B., \& Suen, E. (1991). A method of choosing multiway partitions for classification and decision trees. Journal of Applied Statistics, 18, 49-62.

Csuka, J. \& Ledec, M. (1981). Egg Quality Evaluation by Selected Physical Markers. Rocz. Zoot. T. $8(2), 45-58$.

Çelik, Ş., Şengül, T., İnci, H., Söğüt, B. \& Şengül, A. Y. (2017). Estimation of egg weight from some external and internal quality characteristics in quail by using various data mining algorithms. Indian Journal of Animal Sciences, 87(12), 1524-1530. 
Çelik, Ş. \& Yılmaz, O. (2018). Prediction of body weight of Turkish Tazi Dogs using Data Mining techniques: Classification and Regression Tree (CART) and Multivariate Adaptive Regression Splines (MARS). Pakistan Journal of Zoology, 50(2), 575-583.

Doğan, İ. (2003). Holştayn 1rkı ineklerde süt verimine etki eden faktörlerin CHAID analizi ile incelenmesi. Ankara Üniversitesi Veteriner Fakültesi Dergisi, 50, 65-70.

Duru, M., Duru, A. A., Karadaş, K., Eyduran, E., Cinli, H. \& Tariq, M. M. (2017). Effect of Carrot (Daucus carota) leaf powder on external and internal egg characteristics of Hy-Line White Laying hens. Pakistan J. Zool., 49(1), 125-132.

Eyduran, E., Zaborski, D., Waheed, A., Celik, S., Karadas, K. \& Grzesiak, W. (2017). Comparison of the Predictive Capabilities of Several Data Mining Algorithms and Multiple Linear Regression in the Prediction of Body Weight by Means of Body Measurements in the Indigenous Beetal Goat of Pakistan. Pakistan Journal of Zoology, 49(1), 273-282.

Eyduran, E., Akın, M. \& Eyduran, S. P. (2019). Application of Multivariate Adaptive Regression Splines in Agricultural Sciences Through $R$ Software. Nobel Bilimsel Eserler Sertifika No: 20779, Ankara. ISBN: 978-605-2149-81-2.

Gevrekçi, Y. \& Takma, Ç. (2018). A Comparative Study for Egg Production in Layers by Decision Tree Analysis. Pakistan J. Zool., 50(2), 437-444.

Grzesiak, W. \& Zaborski, D. (2012). Examples of The Use of Data Mining Methods in Animal Breeding. (Book) ISBN 978-953-51-0720-0. Additional information is available at the end of the chapter.

Khan, M. A., Tariq, M. M., Eyduran, E., Tatliyer, A., Rafeeq, M., Abbas, F., Rashid, N., Awan, M. A., Javed, K. (2014). Estimating body weight from several body measurements in Harnai sheep without multicollinearity problem. J. of Animal Plant Science, 24(1), 120--126.

Koyuncugil, A. S. (2007). Borsa Şirketlerinin Sektörel Risk Profillerinin Veri Madenciliğiyle Belirlenmesi. Sermaye Piyasası Kurulu Araştırma Raporu, Araştırma Dairesi, Ankara.

Mendeş, M. \& Akkartal, E. (2009). Regression tree analysis for predicting slaughter weight in broilers. Italian Journal of Animal Science, 8, 615-624.

Nisbet, R., Elder, J. \& Miner, G. (2009). Handbook of Statistical Analysis and Data Mining Applications. Canada.

Oguntunji, A. O. (2017). Regression tree analysis for predicting body weight of Nigerian Muscovy duck (Cairina moschata). Genetika, 49(2), 743-753.

Orhan, H., Eyduran, E., Tatliyer, A. \& Saygıc1, H. (2016). Prediction of egg weight from egg quality characteristics via ridge regression and regression tree methods. Revista Brasileira de Zootecnia, 45(7), 380-385.

Takma, C., Atıl, H. \& Aksakal, V. (2012). Comparison of multiple linear regression and artificial neural network models goodness of fit to lactation milk yields. Kafkas Üniversitesi Veteriner Fakültesi Dergisi, 18, 941-944. 